\title{
Hydrocortisone Sodium Succinate
}

National Cancer Institute

\section{Source}

National Cancer Institute. Hydrocortisone Sodium Succinate. NCI Thesaurus. Code

C1819.

The sodium salt of hydrocortisone succinate with glucocorticoid property.

Hydrocortisone sodium succinate is chemically similar to the endogenous hormone that stimulates anti-inflammatory and immunosuppressive activities, in addition to exhibiting minor mineralocorticoid effects. This agent binds to intracellular glucocorticoid receptors and is translocated into the nucleus, where it initiates the transcription of glucocorticoidresponsive genes, such as various cytokines and lipocortins. Lipocortins inhibit phospholipase A2, thereby blocking the release of arachidonic acid from membrane phospholipids and preventing the synthesis of prostaglandins and leukotrienes, both potent mediators of inflammation. 